\title{
Developmental Dysplasia of the Hip (DDH) in Saudi Arabia: Time to Wake up. A Systematic Review (1980-2018)
}

\author{
Mir Sadat-Ali $\mathbb{1}$ \\ Department of Orthopaedic Surgery, College of Medicine, Imam Abdulrahman Bin Faisal University, Dammam and King Fahd \\ Hospital of the University, Al Khobar, KSA \\ Email: smali@iau.edu.sa,drsadat@hotmail.com
}

How to cite this paper: Sadat-Ali, M. (2020) Developmental Dysplasia of the Hip $(\mathrm{DDH})$ in Saudi Arabia: Time to Wake up. A Systematic Review (1980-2018). Open Journal of Epidemiology, 10, 125-131. https://doi.org/10.4236/ojepi.2020.102011

Received: January 30, 2020

Accepted: April 23, 2020

Published: April 26, 2020

Copyright (๑) 2020 by author(s) and Scientific Research Publishing Inc. This work is licensed under the Creative Commons Attribution International License (CC BY 4.0).

http://creativecommons.org/licenses/by/4.0/ (c) (i) Open Access

\begin{abstract}
The objective of this systematic literature review was to assess the incidence of DDH among the Saudi Arabian population. Methods: A systematic review was performed for all the published articles in the English language literature on DDH in Saudi Arabia. Data sources were PubMed Medline (1980-2018) (http://www.ncbi.nlm.nih.gov/pubmed/), Ovid Medline (1980-2018), EMBASE MEDLINE (1980 to May 2018), EMBASE (1991 to May 2018), the Cochrane Central Register of Controlled Trials and Cochrane Database of Systematic Reviews, the Science Citation Index (1966 to May 2018), published data from the Saudi Medical Journal (1985-2018) and Annals of Saudi Medicine (1985-2018). The author independently reviewed articles and abstracted the data. The key words used were Saudi Arabia developmental dysplasia of the hip ORDDH, congenital hip dislocation or congenital subluxation of the hip, and congenital dysplasia of the hip. Results: The authors identified 18 potentially relevant articles published in the last 38 years, and 10 met the inclusion criteria. The 10 studies analyzed included 2037 studies of infants diagnosed with DDH; and they gave an average incidence of 10.46/1000. Two studies (303 subjects) did not report the affected gender; in the remaining 338 were boys and 1396 were girls and one study did not report the side of affection. The majority presented after 12 months of age. The right side was affected in $532(27.2 \%)$ affected, 734 (37.6\%) were left side and 687 (35.2\%) infants were affected bilaterally. Consanguinity, breech presentation, and family history were found to be the risk factors in $32.9 \%, 17.3 \%$, and $23.6 \%$ of the patients, respectively. Conclusions: There is paucity of available literature on DDH in Saudi Arabia. New strategies have to be developed that include mandatory screening programs in all hospitals (private and public) so that more children can be treated by nonsurgical methods.
\end{abstract}




\section{Keywords}

Developmental Dysplasia of the Hip, Congenital Hip Dislocation, Congenital Subluxation of the Hip, Congenital Dysplasia of the Hip, Saudi Arabia

\section{Introduction}

Development dysplasia of the hip (DDH) describes the entire array of deformities from subluxation and instability, frank dislocation, and dysplasia of the femoral head and acetabulum [1] [2] [3]. The incidence of DDH varies in different countries, from dislocated hip at birth (1 - 5 per 1000 live births) to subluxation and dysplasia (10 per 1000) [4] [5] [6]. Early diagnosis and appropriate treatment are important in providing children with hips that are as normal as possible. In many children, the diagnosis is delayed and the patients require surgery that has a list of complications leading to low functional outcome and quality of life. Many risk factors for DDH have been identified, such as swaddling [7] [8], consanguineous marriage [9] [10], and breech delivery [11] [12] [13] (the first two being under control of the parents).

The epidemiology of any disease is important to find the incidence and risk factors and implement preventive measures so that early diagnosis and treatment could lead to a reduction in heightened morbidity in later life. DDH is unfortunately common in Saudi Arabian children, and swaddling and consanguineous marriage still remain high.

In the recent past there have been no reports on epidemiology of DDH from Saudi Arabia, hence this systematic review was done to shed some light on the incidence of DDH and common demographic characteristics of the disease. Recommendations could be made based on the results.

\section{Methodology}

A systematic review was performed for all the published articles in English language literature on DDH in Saudi Arabia, between Data sources used were PubMed Medline (1980-2018) (http://www.ncbi.nlm.nih.gov/pubmed/), Ovid Medline (1980-2018), EMBASE MEDLINE (1980 to May 2018), EMBASE (1991 to May 2018), the Cochrane Central Register of Controlled Trials and Cochrane Database of Systematic Reviews (1980 to May 2018), and the Science Citation Index (1966 to May 2018), published data from the Saudi Medical Journal (1985-2018) and Annals of Saudi Medicine (1985-2018). Author independently reviewed articles and abstracted the data. The key words used were Saudi Arabia developmental dysplasia of the hip or DDH and congenital hip dislocation $(\mathrm{CDH})$, congenital subluxation of the hip, congenital dysplasia of the hip. Inclusion criteria was all studies which reported DDH in the study period and exclusion criteria was set for those manuscripts dealing with management. Children at the time of presentation with either subluxation or dislocation were included. 
The data was entered in the database and analyzed using SPSS Inc. version 21. The data were expressed as mean \pm SD. Statistically significant differences between the different groups were determined with the Student's t-test.

\section{Results}

The author identified 18 potentially relevant articles over a 38 -year-period and 10 met the inclusion criteria. The 10 studies analyzed included a 2037 study of infants diagnosed with DDH, but only 5 studies were prospective and of true epidemiological nature; they gave an average incidence of 10.46/1000 (Table 1). These 5 studies have been reported from all geographical provinces of the country. Fifty percent were prospective studies. Two studies (303 subjects) did not give the affected gender; in the remaining 338 were boys and 1396 were girls and one study did not report the side of affection. The majority presented after 12 months of age. Of the 1953 infant patients, in 532 (27.2\%) affected side right, 734 (37.6\%) were left side and 687 (35.2\%) infants were affected bilaterally (Table 2). Consanguinity, breech presentation, and family history were found to be the risk factors in $32.9 \%, 17.3 \%$, and $23.6 \%$ of patients, respectively (Table 3 ).

Table 1. Demographic data of the 10 studies analyzed.

\begin{tabular}{|c|c|c|c|c|c|c|}
\hline No. & Authors & $\begin{array}{l}\text { Study } \\
\text { Type }\end{array}$ & $\begin{array}{l}\text { Number of } \\
\text { Patients }\end{array}$ & Prevalence/1000 & Female & Male \\
\hline 1. & Mufti (1988) [14] & $\mathrm{P}$ & 137 & NR & NR & NR \\
\hline 2. & Al-Umran et al. (1988) [15] & $\mathrm{P}$ & 37 & 4.3 & 23 & 14 \\
\hline 3. & Khan and Benjamin (1992) [16] & $\mathrm{P}$ & 81 & 36.5 & 58 & 23 \\
\hline 4. & Mirdad (2002) [17] & $\mathrm{R}$ & 300 & 3.5 & 235 & 65 \\
\hline 5. & Kremli et al. (2003) [10] & $\mathrm{P}$ & 600 & NR & 513 & 87 \\
\hline 6. & Kurdi et al.(2016) [18] & $\mathrm{R}$ & 166 & 4.90 & NR & NR \\
\hline 7. & Alhunaishel et al. (2016) [19] & $\mathrm{R}$ & 136 & NR & 106 & 30 \\
\hline 8. & Al-Anazi et al. (2017) [20] & $\mathrm{P}$ & 300 & 3.1 & 220 & 80 \\
\hline 9. & Al-Mohrej et al. (2017) [21] & $\mathrm{R}$ & 176 & NR & 151 & 25 \\
\hline 10. & Assaf (2018) [22] & $\mathrm{R}$ & 104 & NR & 90 & 14 \\
\hline
\end{tabular}

$\mathrm{NR}=$ Not Reported, $\mathrm{P}=$ Prospective $\mathrm{R}=$ Retrospective .

Table 2. Age of presentation and affected side.

\begin{tabular}{|c|c|c|c|c|c|}
\hline & Authors & $\begin{array}{c}\text { Average Age of } \\
\text { presentation }\end{array}$ & Right & Left & Bilateral \\
\hline 1. & Mufti (1988) [14] & NR & 34 & 44 & 0 \\
\hline 2. & Al-Umran et al. (1988) [15] & 1 day & 29 & 52 & 37 \\
\hline 3. & Khan and Banjamin (1992) [16] & 1 day & 9 & 46 & 26 \\
\hline 4. & Mirdad (2002) [17] & NR & 67 & 82 & 127 \\
\hline 5. & Kremli (2003) [10] & NR & 159 & 223 & 218 \\
\hline
\end{tabular}




\section{Continued}

\begin{tabular}{cccccc}
\hline 6. & Kurdi et al. (2016) [18] & NR & NR & NR & NR \\
7. & Alhunaishel et al. (2016) [19] & $<14$ years & 27 & 26 & 91 \\
8. & Al-Anazi et al. (2017) [20] & 12 months & 85 & 125 & 40 \\
9. & Al-Mohrej et al. (2017) [21] & 3 months & 50 & 44 & 88 \\
10. & Assaf (2018) [22] & $<24$ months & 72 & 92 & 60 \\
\hline
\end{tabular}

$\mathrm{NR}=$ Not Reported

Table 3. Risk Factors for DDH with percentages.

\begin{tabular}{|c|c|c|c|c|}
\hline & Authors & Consanguinity (\%) & $\begin{array}{c}\text { Breech } \\
\text { Presentation (\%) }\end{array}$ & Family History (\%) \\
\hline 1. & Mufti (1988) [14] & 30 & 37.8 & NR \\
\hline 2. & Al-Umran et al. (1988) [15] & NR & 13.6 & 6.8 \\
\hline 3. & Mirdad (2002) [16] & 7.3 & 10 & 21.3 \\
\hline 4. & Kremli et al. (2003) [10] & 49.3 & 11.4 & 43 \\
\hline 5. & Alhunaishel et al. (2016) [18] & NR & 11 & 12.5 \\
\hline 6. & Al-Anazi et al. (2017) [19] & 45 & 20 & 23.3 \\
\hline
\end{tabular}

NR $=$ Not Reported

\section{Discussion}

Based on the analyzed literature, the incidence of DDH in Saudi Arabia was 10.46/1000. Girls were more affected than boys, and the left side was the site of DDH in the majority. There are about 2,135,417 Saudi children younger than 4 years, meaning on average there are 22,336 cases at a given time in the country. In 2017, Saudi Arabian women delivered 680,615 live births, making another 7119 new cases [22].

The pattern of the DDH in this review did not differ from the rest of the world in 3 parameters: gender, side of the affected hip, and family history. In a multicenter study involving 4 countries (Australia, Canada, United States and United Kingdom), Mulpuri et al found similar results [23]. One parameter that did not correspond to this study was breech delivery as a risk factor. If DDH is not diagnosed and treated early, then the long-term results of late treatment lead to unfavorable consequences. One of the most common complications is secondary end-stage osteoarthritis in younger patients leading to early total hip arthroplasty (THA). THA in such patients requires a highly demanding procedure and has a high failure rate [24] [25]. Patients who are screened and diagnosed early and treated nonsurgically have a success rate of over $90 \%$. Within Saudi Arabia, there is a wide-ranging variability of presentation from newborn to 6 years, making treatment decisions difficult and outcomes unpredictable. To avoid short- and long-term complications, there is couple of ways of solving this issue. First, we need to perform a prospective, multicenter epidemiological study in the country to get to the proper incidence. The advantages of prospective, multicenter stu- 
dies are well known, and the study will show the depth of the problem so that pediatric orthopedic surgeons and health authorities will be required to make appropriate decisions [26] [27]. Second, mandatory neonatal screening is required in all hospitals, irrespective of location and size. Without a proper report of the screening from the hospital where a child is born, a birth certificate should not be issued. This seems a draconian move, but in the long run it will help children, parents, and the country as a whole. This was how mandatory vaccinations for newborns were achieved. Some may argue the routine screening may not solve all the problems related to $\mathrm{DDH}$, but the routine screening could later be converted to a selective screening program, which has given satisfactory results in the United Kingdom [28]. Moreover children with a risk factor can be screened till walking age.

This review has definite limitations, one being its small size due to a low number of studies published on this subject. However this report highlights the need and encourages pediatric orthopedic surgeons, pediatricians, and neonatologists to perform more studies and implement strategies to limit DDH in the coming generations so that fewer children need arthroplasty surgery. Physicians and surgeons of the country should not only manage and operate on children with DDH but should also find new strategies by which a newborn should not leave hospitals without diagnosis and proper treatment for $\mathrm{DDH}$.

\section{Conclusion}

In conclusion, this analysis shows that the prevalence of DDH in Saudi Arabia is $10.46 / 1000$ live births, with risk factors of consanguinity, breech presentation, and family history. This study further highlights the reluctance of many trained pediatric orthopedic surgeons to perform epidemiological studies on DDH, which is proved by 5 reports in last 3 decades. Additional multicenter, prospective studies are needed to address the correct incidence, and more efforts are needed to screen newborns for DDH and treat them before they leave the hospitals.

\section{Funding}

There was no funding for this project.

\section{Conflicts of Interest}

The authors declare no conflicts of interest regarding the publication of this paper.

\section{References}

[1] Guille, J.T., Pizzutillo, P.D. and MacEwen, G.D. (2000) Development Dysplasia of the Hip from Birth to Six Months. The Journal of the American Academy of Orthopaedic Surgeons, 8, 232-242. https://doi.org/10.5435/00124635-200007000-00004

[2] Aronsson, D.D., Goldberg, M.J., Kling, T.F. and Roy, D.R. (1994) Developmental Dysplasia of the Hip. Pediatrics, 94, 201-208. 
[3] Vitale, M.G. and Skaggs, D.L. (2001) Developmental Dysplasia of the Hip from Six Months to Four Years of Age. The Journal of the American Academy of Orthopaedic Surgeons, 9, 401-411. https://doi.org/10.5435/00124635-200111000-00005

[4] Woodacre, T., Ball, T. and Cox, P. (2016) Epidemiology of Developmental Dysplasia of the Hip within the UK: Refining the Risk Factors. Journal of Children's Orthopaedics, 10, 633-642. https://doi.org/10.1007/s11832-016-0798-5

[5] American Academy of Pediatrics (2000) Clinical Practice Guideline: Early Detection of Developmental Dysplasia of the Hip. Committee on Quality Improvement, Subcommittee on Developmental Dysplasia of the Hip. American Academy of Pediatrics. Pediatrics, 105, 896-905. https://doi.org/10.1542/peds.105.4.896

[6] Bialik, V., Bialik, G.M., Blazer, S., Sujov, P., Wiener, F. and Berant, M. (1999) Developmental Dysplasia of the Hip: A New Approach to Incidence. Pediatrics, 103, 93-99. https://doi.org/10.1542/peds.103.1.93

[7] Clarke, N.M.P. (2014) Swaddling and Hip Dysplasia: An Orthopaedic Perspective. Archives of Disease in Childhood, 99, 5-6. https://doi.org/10.1136/archdischild-2013-304143

[8] Pratt, W., Freiberger, R.H. and Arnold, W.D. (1982) Untreated Congenital Hip Dysplasia in the Navajo. Clinical Orthopaedics and Related Research, 162, 69-77. https://doi.org/10.1097/00003086-198201000-00012

[9] Guner, S.I., Guner, S., Peker, E., Ceylan, M.F., Guler, A., Turktas, U., et al. (2013) Are Consanguineous Marriage and Swaddling the Risk Factors of Developmental Dysplasia of the Hip? The Journal of Membrane Biology, 246, 115-119. https://doi.org/10.1007/s00232-012-9509-4

[10] Kremli, M.K., Alshahid, A.H., Khoshhal, K.I. and Zamzam, M.M. (2003) The Pattern of Developmental Dysplasia of the Hip. Saudi Medical Journal, 24, 1118-1120.

[11] Schwend, R.M., Shaw, B.A. and Segal, L.S. (2014) Evaluation and Treatment of Developmental Hip Dysplasia in the Newborn and Infant. Pediatric Clinics of North America, 61, 1095-1107. https://doi.org/10.1016/j.pcl.2014.08.008

[12] Bache, C.E., Clegg, J. and Herron, M. (2002) Risk Factors for Developmental Dysplasia of the Hip: Ultrasonographic Findings in the Neonatal Period. Journal of Pediatric Orthopaedics B, 11, 212-218. https://doi.org/10.1097/01202412-200207000-00004

[13] Imrie, M., Scott, V., Stearns, P., Bastrom, T. and Mubarak, S.J. (2010) Is Ultrasound Screening for DDH in Babies Born Breech Sufficient? Journal of Children's Orthopaedics, 4, 3-8. https://doi.org/10.1007/s11832-009-0217-2

[14] Mufti, M.H. (1988) Prime Factors in the Etiology of Congenital Dislocation of the Hip and Talipes Equinovarus in Riyadh. Annals of Saudi Medicine, 8, 29-34. https://doi.org/10.5144/0256-4947.1988.29

[15] Al-Umran, K., Ahberg, A., Dawodu, A., El-Mouzan, M. and Ahmad, F. (1988) Neonatal Screening for Hip Instability: Five Years' Experience. Annals of Saudi Medicine, 8, 425-429. https://doi.org/10.5144/0256-4947.1988.425

[16] Mirdad, T. (2002) Incidence and Pattern of Congenital Dislocation of the Hip in Aseer Region of Saudi Arabia. West African Journal of Medicine, 21, 218-222. https://doi.org/10.4314/wajm.v21i3.28034

[17] Kurdi, Y., Chaudhary, A., Hussein, D., Nooh, A., Anam, E. and Ahmed, H. (2016) Development Dysplasia of the Hip in the Western Region of Saudi Arabia: Prevalence, Risk Factors and Kinder-Ship Assessment. Health Care: Current Reviews, 4, 67. 
[18] Alhunaishel, M.A., Ahmed, F.E., Alotaibi, M.G., Alqahtani, B.S. and Al Zughaibi, M.A. (2016) The Morphology of DDH in Saudi Children in Riyadh, KAMC. Journal of Epidemiology and Public Health Reviews, 1. https://doi.org/10.16966/2471-8211.117

[19] Alanazi, H.M., Alenezi, O.T., El-Fetoh, N.M.A., Ali, G.Y., Albaqawi, A.S., Altaleb, F.F., et al. (2017) Pattern of Congenital Dislocation of the Hip in Arar City, Northern Saudi Arabia. Journal of Health, Medicine and Nursing, 43, 35-40.

[20] Al-Mohrej, O.A., Alsarhani, W.K., Al-Ayedh, N.K., Al-Ghamdi, A.M., Masudi, E.M. and Al-Saif, S.A. (2017) Characteristics of Developmental Dysplasia of the Hip at a Tertiary Hospital in Riyadh, Saudi Arabia. Journal of Health Specialties, 5, 87-90. https://doi.org/10.4103/2468-6360.205076

[21] Assaf, N. (2018) Prediction of the Requirement of Open Reduction for Developmental Dysplasia of the Hip. Journal of International Medical Research, 46, 54-61. https://doi.org/10.1177/0300060517717357

[22] http://www.cdsi.gov.sa/english/index.php

[23] Mulpuri, K., Schaeffer, E.K., Kelley, S.P., Castañeda, P., Clarke, N.M., Herrera-Soto, J.A., et al. (2016) What Is the Impact of Center Variability in a Multicenter International Prospective Observational Study on Developmental Dysplasia of the Hip? Clinical Orthopaedics and Related Research, 474, 1138-1145. https://doi.org/10.1007/s11999-016-4746-y

[24] Engesaeter, L.B., Furnes, O. and Havelin, L.I. (2008) Developmental Dysplasia of the Hip-Good Results of Later Total Hip Arthroplasty: 7135 Primary Total Hip Arthroplasties after Developmental Dysplasia of the Hip Compared with 59,774 Total Hip Arthroplasties in Idiopathic Coxarthrosis Followed for 0 to 15 Years in the Norwegian Arthroplasty Register. The Journal of Arthroplasty, 23, 235-240. https://doi.org/10.1016/j.arth.2007.03.023

[25] Narayanan, U., Mulpuri, K., Sankar, W.N., Clarke, N.M.P., Hosalkar, H. and Price, C.T. (2015) Reliability of a New Radiographic Classification for Developmental Dysplasia of the Hip. Journal of Pediatric Orthopaedics, 35, 478-484. https://doi.org/10.1097/BPO.0000000000000318

[26] Engesaeter, L.B., Engesaeter, I.O., Fenstad, A.M., Havelin, L.I., Karrholm, J., Garellick, G., Pedersen, A.B. and Overgaard, S. (2012) Low Revision Rate after Total Hip Arthroplasty in Patients with Pediatric Hip Diseases. Acta Orthopaedica, 83, 436-441. https://doi.org/10.3109/17453674.2012.736171

[27] Sochart, D.H. and Porter, M.L. (1997) The Long-Term Results of Charnley Low Friction Arthroplasty in Young Patients Who Have Congenital Dislocation, Degenerative Osteoarthrosis, or Rheumatoid Arthritis. The Journal of Bone and Joint Surgery. American Volume, 79, 1599-1617. https://doi.org/10.2106/00004623-199711000-00001

[28] Price, K.R., Dove, R. and Hunter, J.B. (2013) Current Screening Recommendations for Developmental Dysplasia of the Hip May Lead to an Increase in Open Reduction. The Bone \& Joint Journal, 95, 846-850.

https://doi.org/10.1302/0301-620X.95B6.31461 